\title{
Toll-Like Receptor Responsiveness of Peripheral Blood Mononuclear Cells in Young Women with Dysmenorrhea
}

This article was published in the following Dove Press journal: Journal of Pain Research

\author{
Susan F Evans $\mathbb{D}^{\prime}$ \\ Yuen $\mathrm{H}$ Kwok $\mathbb{D}^{2}$ \\ Ann Solterbeck (iD $)^{3}$ \\ Jiajun Liu $^{2}$ \\ Mark R Hutchinson (D) ${ }^{1,4}$ \\ $M$ Louise Hull $\mathbb{D i D}^{5}$ \\ Paul E Rolan ${ }^{6}$ \\ 'Adelaide Medical School, University of \\ Adelaide, Adelaide, South Australia, \\ Australia; ${ }^{2}$ Faculty of Health Science, \\ University of Adelaide, Adelaide, South \\ Australia, Australia; ${ }^{3}$ Statistical \\ Revelations, Melbourne, Victoria, \\ Australia; ${ }^{4}$ Australian Research Council \\ Centre of Excellence for Nanoscale \\ BioPhotonics, University of Adelaide, \\ Adelaide, South Australia, Australia; \\ ${ }^{5}$ Robinson Research Institute, School or \\ Pediatrics and Reproductive Health, \\ University of Adelaide, Adelaide, South \\ Australia, Australia; ${ }^{6}$ School of Medicine, \\ University of Adelaide, Adelaide, South \\ Australia, Australia
}

Correspondence: Susan F Evans Tel +6I 418849895

Emailsusan.evans@adelaide.edu.au
Purpose: Dysmenorrhea is a common disorder that substantially disrupts the lives of young women. To determine whether there is evidence of activation of the innate immune system in dysmenorrhea and whether the degree of activation may be used as a biomarker for pain, we compared the responsiveness of peripheral blood mononuclear cells (PBMCs) to toll-like receptor (TLR) 2 or 4 stimulation. We also investigated whether this effect is modulated by the use of the oral contraceptive pill (OC).

Patients and Methods: Fifty-six women aged 16-35 years, with either severe or minimal dysmenorrhea, and use or non-use of the OC, were enrolled. PBMCs were collected on two occasions in a single menstrual cycle: the menstrual phase and the mid-follicular phase. PBMCs were exposed to lipopolysaccharide (LPS), a TLR4 agonist, and PAM3CSK4 (PAM), a TLR2 agonist, and the resulting interleukin-1beta $(\mathrm{IL}-1 \beta)$ output was determined. Statistical analysis compared the EC50 between groups as a measure of TLR responsiveness of PBMCs.

Results: The key finding following LPS stimulation was a pain effect of dysmenorrhea $(\mathrm{p}=0.042)$ that was independent of use or non-use of OC, and independent of day of testing. Women with dysmenorrhea showed a large 2.15 -fold $(95 \%$ CI $-4.69,-0.09)$ increase in IL-1 $\beta$ release when compared with pain-free participants across both days.

Conclusion: This is the first study to demonstrate an ex vivo immune relationship in women with dysmenorrhea-related pelvic pain. It provides evidence for the potential of immune modulation as a novel pharmacological target for future drug development in the management of dysmenorrhea.

Keywords: pain, chronic pain, oral contraceptive pill, endometriosis, pelvic pain, IL-1 $\beta$

\section{Introduction}

Dysmenorrhea, or period pain, is a distressing condition that has a global medical, personal, societal and economic impact. Almost every woman will experience dysmenorrhea at some time in her life, ${ }^{1}$ although the severity, duration and persistence will vary widely. A meta-analysis of 15 studies worldwide ${ }^{2}$ revealed the substantial life impact of dysmenorrhea in young women. Pain sufficient to cause distress or absenteeism affected between $2 \%$ and $29 \%$ of young women, depending on study design and the severity of dysmenorrhea considered. In addition, dysmenorrhea commonly resulted in emergency department presentation, hospital admission, ${ }^{3}$ reduced educational achievement, impaired mental health, ${ }^{4,5}$ reduced workplace productivity, ${ }^{6}$ disturbed sleep, ${ }^{7}$ and reduced quality of life. ${ }^{8}$ Dysmenorrhea frequently precedes, ${ }^{9}$ and is believed to be an etiological factor in, the development of persistent pelvic pain in some 
women. $^{10-12}$ Hardi et $\mathrm{al}^{9}$ retrospectively reviewed 100 women with dysmenorrhea-predominant persistent pelvic pain, and found that dysmenorrhea predated the development of persistent pain by between 1 and 30 years.

Current medical management options include the oral contraceptive pill (OC), non-steroidal anti-inflammatory medications (NSAIDs), or progestogens. However, many young women find these options to be ineffective, contraindicated or unacceptable. ${ }^{13}$ There is an unmet need for new, effective treatments for dysmenorrhea.

Traditionally, dysmenorrhea in women has been classified as either primary, where no organic cause has been identified, and secondary, where an associated condition, such as endometriosis is present. However, despite the recognized association and common co-existence of endometriosis with dysmenorrhea, there is no reliable correlation between the severity of endometriosis lesions and the severity of pain. ${ }^{14}$ In previous work, our group has demonstrated the strong association between dysmenorrhea and a range of symptoms, both within and outside the pelvis, that include: headache, fatigue, anxiety, low mood, bladder or bowel symptoms, and nausea. ${ }^{15}$ These factors strongly suggest the presence of additional elements affecting the experience of dysmenorrhea. Compelling epidemiological, clinical and experimental evidence in both human and animal studies demonstrates that increased peripheral and central nervous system (CNS; glial) immune system activity, via Toll-like receptors (TLRs), is involved in the development of persistent pain conditions. ${ }^{16}$ In this paper, we propose that immune pathology may also be present in women affected by dysmenorrhea, whether or not an associated condition such as endometriosis is present, and that activation of the immune system in these women occurs via TLRs. Therefore, the innate immune reactivity of an individual's peripheral blood immune cells may provide insights into the mechanism behind their disease state.

TLRs are a family of receptors found on the surface membrane of cells of the innate immune system, such as macrophages, glia and astrocytes. They recognize molecular patterns typically associated with microbial pathogens and facilitate an immune response with the release of cytokines, including interleukin-1beta (IL-1 $\beta$ ), both peripherally and in the spinal cord. Lipopolysaccharide (LPS), also known as endotoxin, is a component of the cell wall of gram-negative bacteria, which elicits robust immune responses in animals via TLR4 receptors. PAM3CSK4 (PAM) is a synthetic lipopeptide that elicits strong immune responses via TLR2 receptors. Altered TLR inflammatory responses have been demonstrated in visceral medical conditions characterized by persistent pain, such as inflammatory bowel disease and painful bladder syndrome. ${ }^{17,18}$ Macrophages are cells of the innate immune system that originate from peripheral blood monocytes and are present in almost all tissues. These cells alter their physiology, infiltrate tissues and secrete cytokines including IL-1 $\beta^{19,20}$ in response to inflammatory mediators.

We hypothesize that peripheral blood mononuclear cells (PBMCs) from women with severe dysmenorrhea exhibit enhanced IL- $1 \beta$ release following stimulation of either TLR4 or TLR2 receptors when compared with normal (control) women with minimal, or no, dysmenorrhea. Where confirmed, this offers the potential for the responsiveness of PBMCs to TLR stimulation to be used as a biomarker for pain in future research of dysmenorrhea treatment options. We also hypothesize that TLR responsiveness is modulated by use of the OC, and by the presence or absence of severe pain at the time of testing.

\section{Materials and Methods Study Design}

This is an observational clinical and laboratory study, with samples taken from women at two stages of their menstrual cycle. This study was approved by the Human Research Ethics Committee of the Royal Adelaide Hospital, Adelaide, South Australia. HREC/14/RAH/63. RAH Approval No. 140217. The study was conducted in accordance with the Declaration of Helsinki. ${ }^{21}$

\section{Participants}

The target population consisted of girls and women aged between 16 and 35 years of age. Potential participants were invited to complete a Survey Monkey Questionnaire when they responded to recruitment notices displayed to the general public or following an invitation to enroll through a private medical clinic, Pelvic Pain SA, Adelaide, Australia. After selection based on the eligibility criteria, participants were provided with a study information sheet. Study exclusion criteria (Table 1) ensured that women possessing factors that might influence inflammation, TLR receptor response, the immune system, or the severity of dysmenorrhea were excluded from the study. Eligible participants from the general public were offered the opportunity of an initial phone interview to provide further information about the study, to obtain consent for further participation in 
Table I Study Exclusion Criteria

\begin{tabular}{|l|}
\hline Dysmenorrhoea on Day I-2 reported as 4-6 on a I0-point scale \\
\hline Menstrual cycle length less than 26 or more than 30 days \\
\hline Irregular menstrual cycles \\
\hline Previous pregnancy \\
\hline Use of reproductive hormones (apart from OC) \\
\hline Use of levonorgestrel-releasing intrauterine device \\
\hline Use of thyroxine, insulin or corticosteroids \\
\hline BMI less than 16 or more than 30 \\
\hline $\begin{array}{l}\text { Inflammatory process, surgical procedure or infection in previous } 4 \\
\text { weeks }\end{array}$ \\
\hline Renal, hepatic, cardiac or auto-immune disease \\
\hline Use of immunosuppressant medications \\
\hline $\begin{array}{l}\text { Use of medications affecting TLR responsiveness, including } \\
\text { amitriptyline and minocycline }\end{array}$ \\
\hline $\begin{array}{l}\text { Use of analgesics including anti-inflammatory drugs, opioids or } \\
\text { paracetamol for } 5 \text { drug half-lives prior to testing }\end{array}$ \\
\hline Use of alcohol for 24 hrs prior to testing \\
\hline Use of opioids or marijuana for 30 days prior to testing \\
\hline Inability to read or comprehend written information provided \\
\hline
\end{tabular}

the study, and to arrange a screening assessment visit with the Principal Investigator (PI). Figure 1 shows the Enrolment Flow Chart for study inclusion.

Three hundred and sixty women completed the online questionnaire, with 105 women choosing to provide their contact details for consideration for study inclusion. Phone interview assessment by the Principal Investigator further excluded 44 women based on the presence of exclusion criteria. Sixty-one women recruited from the general public and five additional women recruited through Pelvic Pain SA, Adelaide, Australia proceeded to the Screening Visit, where they underwent a full clinical assessment, and the appropriate study group allocation was accurately determined. Participants below the age of 18 were interviewed in the presence of their parent or guardian, who co-signed the consent form with the participant. One participant was excluded due to previous pregnancy. Thus, a total of 65 women were enrolled in the study. Nine women were excluded during the study due to a high pre-test level of C-reactive protein (1), use of marijuana (1), irregular menstrual cycles (3), non-attendance for testing (2), insufficiently severe pain (1), and the development of an unrelated neurological illness (1). Fifty-six women satisfied all inclusion and exclusion criteria and completed the testing procedures.

\section{Group Allocation}

Participants were allocated to seven clinical groups at the Screening Visit (Table 2; groups 2A and B combined). Group allocation was determined by the self-reported presence or absence of severe dysmenorrhea, the use or nonuse of the OC, and the self-reported presence of pelvic pain for more, or less, than 15 days per month, as reported at the Screening Visit. Controls were women with selfreported dysmenorrhea of between 0 and 3 on an 11-point numerical scale (NRS) ${ }^{22}$ using anchor points of 0 and 10 , where 0 represented no pain and 10 represented the most severe pain imaginable on the worst day of their menstrual period (Groups 1 and 2). Controls who were OC users (Group 2) were further divided into women who were pain-free prior to use of the OC (Group 2A), and women who had self-reported dysmenorrhea of between 4 and 10 prior to OC use (Group 2B). However, as study results for Group 2A and Group 2B were found to be similar, these groups were combined to form an enlarged Group 2, as illustrated in Table 2.

Dysmenorrhea-based pelvic pain participants (Groups 3, 4, 5 and 6) had self-reported dysmenorrhea of 7-10 on an 11-point NRS on the worst day of their menstrual period. As the number of days affected by pain varied throughout the severe dysmenorrhea cohort, participants with dysmenorrhea were further divided into those with pelvic pain for less than 15 days per month (Groups 3 and 4), and those with pelvic pain for more than 15 days per month (Groups 5 and 6). This provided an estimate of the severity of life impact of their dysmenorrhea-based pelvic pain condition. Dysmenorrheabased pelvic pain participants (Groups 3,4,5 and 6) were further divided based on OC use (non-OC users in Groups 3 and 5; OC users in Groups 4 and 6).

\section{Study Visit Schedule}

Participants were assessed on two occasions during a single menstrual cycle: the menstrual phase (Day 1-2 of their menstrual cycle), a phase associated with high pain in women with dysmenorrhea; and the mid-follicular phase (Day 7-10 of their menstrual cycle), a time associated with low pain in women with dysmenorrhea. At Study Visit 1, participants attended the Pain and Anaesthesia Research Clinic (PARC) of the Royal Adelaide Hospital, Adelaide, Australia on either day 1 or 2 of their menstrual cycle. 


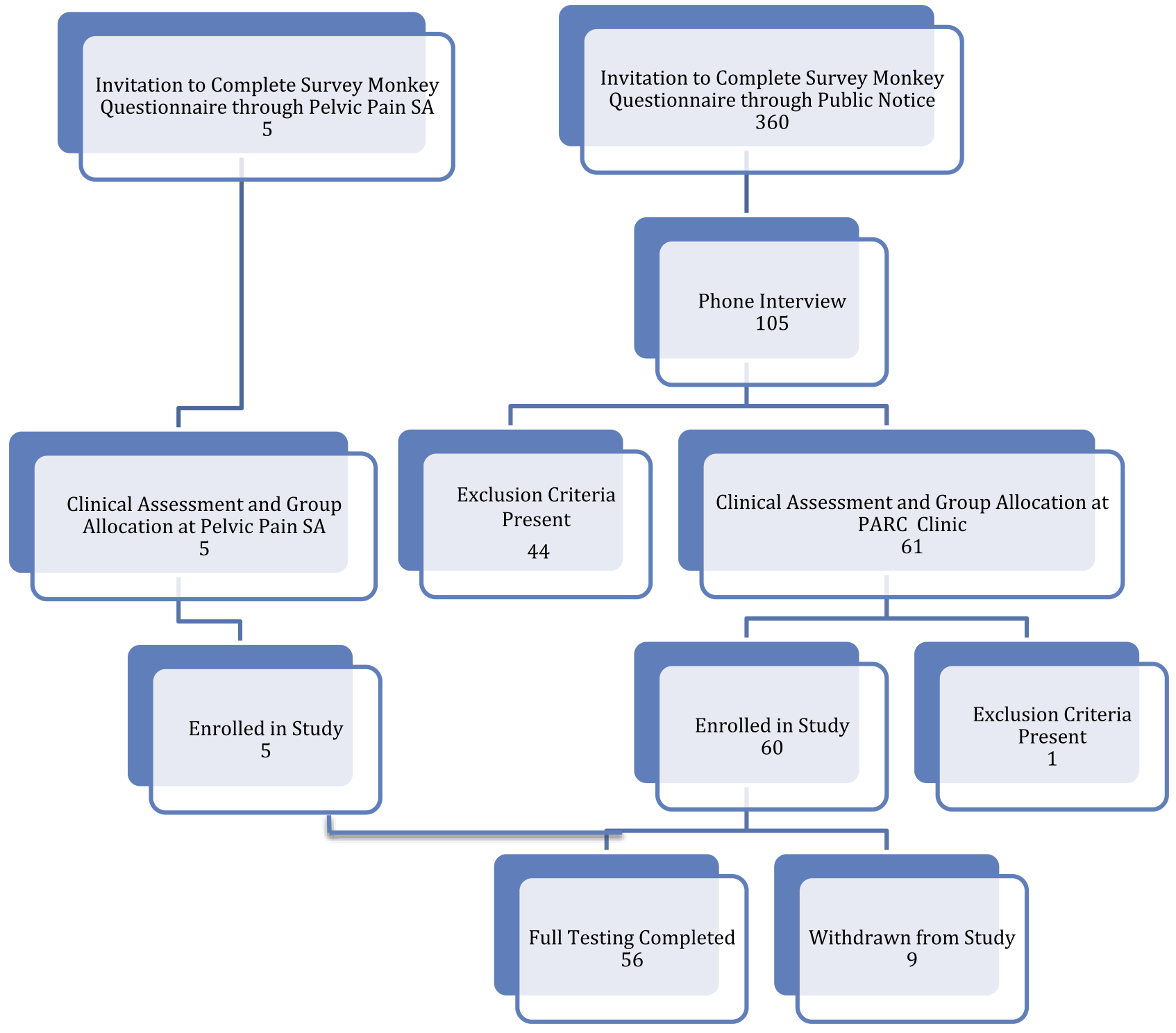

Figure I Enrolment flow chart for participant recruitment and study inclusion.

Participants were expressly requested not to use potentially confounding medications, including non-steroidal antiinflammatory medications, for at least five half-lives of the drug prior to presentation for testing. At their visit, participants were asked to confirm the absence of exclusion criteria including use of confounding medications, report their current pain score at the time of testing, complete a survey of pain symptoms, and provide a blood sample for analysis. Analysis of blood samples included: TLR2 and TLR4 responsiveness of PBMCs, a measurement of C-reactive protein (CRP) levels to exclude the presence of un-recognized pre-test inflammation, and a quantitative assessment of luteinizing hormone (LH) and folliclestimulating hormone (FSH) blood levels to confirm baseline hormonal status on day 1-2. All blood samples were taken between the hours of 0830 and 1200. At Study Visit 2, participants attended PARC on one of day 7, 8, 9 or 10 of their menstrual cycle. The testing regime was undertaken as specified above (study visit 1).

\section{Laboratory Methods Specimen Collection}

At each study visit, $35 \mathrm{~mL}$ of blood was collected. Eight $\mathrm{mL}$ of blood was collected into a tube containing clot activator and serum gel separator for the analysis of CRP, LH and FSH levels (Healthscope Laboratories, Adelaide, Australia). Twenty-seven $\mathrm{mL}$ of blood was collected into tubes containing ethylenediaminetetraacetic 
Table 2 Summary of Group Allocation Criteria and Demographics

\begin{tabular}{|l|l|l|l|l|l|l|l|l|l|}
\hline Group & Description & $\begin{array}{l}\text { Number of } \\
\text { Women }\end{array}$ & $\begin{array}{l}\text { Pain } \\
\text { Reported } \\
\geq \mathbf{7} \text { of 10 }\end{array}$ & $\begin{array}{l}\text { Pelvic Pain } \\
\text { >I5 Days/ } \\
\text { Month }\end{array}$ & $\begin{array}{l}\text { OC } \\
\text { Use }\end{array}$ & $\begin{array}{l}\text { Mean Age } \\
\text { (Years) }\end{array}$ & $\begin{array}{l}\text { Mean } \\
\text { BMI }\end{array}$ & $\begin{array}{l}\text { Pain Score at } \\
\text { Testing } \\
\text { Day I-2 }\end{array}$ & $\begin{array}{l}\text { Pain Score at } \\
\text { Testing } \\
\text { Day 7-I0 }\end{array}$ \\
\hline 1 & Controls: No OC & 8 & - & - & - & 23.6 & 23.9 & 1.25 & 0.25 \\
2 & Controls: OC & 15 & - & - & + & 21.9 & 22.3 & 0.92 & 0.31 \\
3 & Dysmenorrhea: No OC & 7 & + & - & - & 25.7 & 23.1 & 6.4 & 0.4 \\
4 & Dysmenorrhea: OC & 8 & + & - & + & 21.3 & 22.4 & 5.75 & 0.25 \\
5 & Pelvic Pain: No OC & 8 & + & + & - & 22.6 & 22.2 & 6.9 & 1.25 \\
6 & Pelvic Pain: OC & 9 & + & + & + & 22.9 & 20.4 & 6.9 & 3.9 \\
\hline
\end{tabular}

Notes: + = present, - = absent.

Abbreviation: OC, oral contraception.

acid (EDTA), and PBMCs isolated using Optiprep (SigmaAldrich, Castle Hill, NSW, Australia) as directed by the manufacturer, using the mixer flotation method.

\section{Quantification of PBMC Responsiveness to TLR Stimulation}

To test our hypotheses, we utilized the laboratory technique devised by Kwok et al to measure IL-1 $\beta$ release from PBMCs following TLR stimulation. ${ }^{23,24}$ Two analyses were undertaken: one using the TLR4 agonist LPS, and the other using the TLR2 agonist PAM.

Isolated cells were diluted to $1 \times 10^{6}$ cells $\cdot \mathrm{mL}^{-1}$ in enriched RPMI $1640(10 \%(\mathrm{v} / \mathrm{v})$ fetal calf serum and $1 \%$ (v/v) penicillin), and plated into 96 well plates (Nunc, Roskilde, Denmark) using $100 \mu \mathrm{L}$ per well. Sufficient cells were obtained from all participants, and plasma was not collected. As no reference range for LPS or PAM concentration is available for this group, TLR responsiveness was assessed across a range of concentrations. Triplicate wells were treated with a dosage curve of TLR agonists: LPS; $12.5 \mathrm{pg} \cdot \mathrm{mL}^{-1}$ to $10 \mu \mathrm{g} \cdot \mathrm{mL} ;^{-1}$ and PAM $12.5 \mathrm{pg} \cdot \mathrm{mL}^{-1}$ to $1 \mu \mathrm{g} \cdot \mathrm{mL}^{-1}$ (SigmaAldrich, Castle Hill, NSW, Australia). Control wells contained no TLR agonist. Plates were incubated for $20 \mathrm{hrs}$ at $37^{\circ} \mathrm{C}$ and $5 \% \mathrm{CO}_{2}$ in a humidified environment (Thermoline Scientific, Sydney, Australia). IL-1 $\beta$ levels were determined using a commercially available ELISA kit (IL- $1 \beta$ ELISA; BD Bioscience, Australia) according to the manufacturer's instructions. The absorbance was quantified on a BMG Polarstar microplate reader (BMG Labtechnologies, Offenburg, Germany) at $450 \mathrm{~nm}$. The manufacturer's limit of quantification of $0.8 \mathrm{pg} \cdot \mathrm{mL}^{-1}$ was used, with any readings below this removed from further analysis.

\section{Method for Statistical Analysis}

To determine the responsiveness of PBMCs to LPS stimulation, represented by the EC50, concentration-response curves were fitted to an $\mathrm{E}_{\max }$ model using the Hill equation ${ }^{25}$ and a non-linear mixed-effects model approach. The slope parameter was fixed to 1 to reduce the number of parameters to be estimated. The model used was of the form:

$$
\mathrm{E}=\mathrm{E}_{0}+\frac{\mathrm{E}_{\max }{ }^{*} \mathrm{C}}{\mathrm{EC}_{50}+\mathrm{C}}
$$

where $\mathrm{E}_{0}$ is the response $\mathrm{Y}$ at baseline (absence of dose), $\mathrm{E}_{\max }$ is the asymptotic maximum dose effect (maximum effect attributable to the drug), and $\mathrm{EC}_{50}$ is the concentration which produces $50 \%$ of the maximal effect.

Individual $\mathrm{E}_{\max }$ models were fitted for each subject at each timepoint (Day 1-2 or Day 7-10). Before model fitting, individual plots of the concentration-response data collected were used to estimate the $\mathrm{EC}_{50}, \mathrm{E}_{\max }$ and $\mathrm{E}_{\min }$ for each subject at each timepoint, to assess the applicability of an $\mathrm{E}_{\max }$ model. As several participants demonstrated a maximum response at well below the maximum concentration tested, potentially associated with reduced cell stability at higher concentrations of LPS, only concentrations up to the observed maximum response were used in model fitting. For doses above the maximum response, the maximum response observed was imputed to force a plateau and facilitate model fit. All model fitting and all analyses were performed using Statistical Analysis Software (SAS v 9.4). Starting values were set with Max representing the maximum response observed for that participant at that timepoint, and Min representing the minimum response for that participant at that timepoint. From the model, estimated values for $\mathrm{EC}_{50}, \mathrm{E}_{\max }$ and $\mathrm{E}_{\min }$ were obtained for each subject at each timepoint. The results for $\mathrm{EC}_{50}$ were analyzed using a mixed model for repeated measures with $\mathrm{EC}_{50}$ as the outcome variable and day (1-2 or 7-10), OC use (yes or no) and pain (no pain, 
dysmenorrhea $<15$ days per month, dysmenorrhea $>15$ days per month) as factors in the model.

The main effects from the model provide information on the differences in PBMC responsiveness according to the presence of pain (irrespective of OC use or menstrual phase), differences in $\mathrm{PBMC}$ responsiveness according to OC use (irrespective of the presence of pain or menstrual phase) and differences in PBMC responsiveness according to menstrual phase (irrespective of the presence of pain or OC use). Participant was included as a repeated term using a compound symmetry covariance structure. From the model the differences in responsiveness of PBMCs to LPS stimulation were determined, according to the six clinical groups described in Table 2.

During the analysis, variation in the days per month of pain was noted within groups 3, 4, 5 and 6 between that reported at the Screening Visit and that reported at presentation on study test days. For this reason, further analysis was undertaken combining Groups 3 and 5 (pain; no OC use) and Groups 4 and 6 (pain; OC use) together to include participants experiencing pain regardless of the number of pain days per month. This analysis allowed us to consider the effect of three individual factors within the entire participant group: the presence or absence of pain (Pain vs No Pain), the use or non-use of the OC (OC vs No OC), and the menstrual phase of testing (Day 1-2 vs Day 7-10). From the model the differences in Least Squares (LS) mean values for comparisons of interest were obtained with 95\% confidence limits and relevant P-values by factor, as shown in Figure 4.

The model was a reasonable fit, with a few outlier results noted. Outliers were identified through two methods. Using Method 1, the raw mean and standard deviation were obtained, and values outside mean \pm 2 standard deviations were flagged as outliers. Using Method 2, once the model was fitted, the residuals were obtained together with their standard error. Any value outside \pm 2 was flagged as an outlier. The mixed model was then rerun excluding any value identified by either method as an outlier. The overall results were not substantially changed, and further statistical analysis was continued using the full data set with outliers included.

\section{Results}

All participants were aged between 16 and 35 years, had regular menstrual cycles, no previous pregnancies, normal body mass index (BMI) and were in good general health, apart from the presence of dysmenorrhea- predominant pelvic pain. As described in Table 2, and using one-way ANOVA and Kruskal-Wallis post hoc analyses, no significant differences were found for the age $(p=0.52)$, height $(p=0.52)$ or weight $(p=0.68)$ of the women in each group. There were no significant differences in BMI $(p=0.38)$ or age $(p=0.60)$ between those with and without pain, and there were no significant differences in BMI $(p=0.21)$ or age $(p=0.11)$ between users and non-users of the OC. The average menstrual pain score for each group recorded at the time of testing was noted to be less than the maximal pain score predicted by participants during group allocation at the screening visit.

Table 2 summarizes the group allocation criteria and demographics.

\section{IL-I $\beta$ Release Following Stimulation with PAM and LPS}

All participants exhibited minimal IL- $1 \beta$ release in the nonstimulated state. Both TLR4 agonist LPS, and TLR2 agonist PAM3CSK4, induced elevations in IL-1 $\beta$ in the isolated PBMCs from all participants. Inspection of the data showed that the effect size following PAM stimulation was smaller and more variable than the effect size following LPS stimulation (Figures 2 and 3 ). The IL-1 $\beta$ response to LPS stimulation followed a biphasic distribution across the logarithmic concentration range of $12.5 \mathrm{pg} \cdot \mathrm{mL}^{-1}$ to $10 \mu \mathrm{g} \cdot \mathrm{mL}^{-1}$ (Figure 2). A similar direction of response was seen in PBMCs stimulated with PAM across the logarithmic concentration range of $12.5 \mathrm{pg} \cdot \mathrm{mL}^{-1}$ to $1 \mu \mathrm{g} \cdot \mathrm{mL}^{-1}$ (Figure 3) but the response followed a monophasic distribution with wide variability. In view of the smaller effect size and higher variability following PAM stimulation, only LPS responses are analysed further.

\section{Analysis of EC50}

The Least Squares (LS) mean values for $\mathrm{EC}_{50}$ and $\mathrm{E}_{\max }$ for the variables Pain, OC use and Day of testing were obtained from the mixed model. $E_{\max }$ values were variable, consistent with suspected non-specific cellular toxicity at high LPS concentrations. As it is the responsiveness of PBMCs to LPS stimulation that we are investigating, rather than the absolute Il-1 $\beta$ levels, further analysis considers the $\mathrm{LS}$ means for $\mathrm{EC}_{50}$ rather than $\mathrm{E}_{\max }$. $\mathrm{EC}_{50}$ is the outcome variable we have used to compare the responsiveness of PBMCs to TLR4 stimulation with LPS between participants.

The LS mean values for $\mathrm{EC}_{50}$ by factor with $\mathrm{p}$ value are displayed in Table 3 and plotted in Figure 4. The difference 

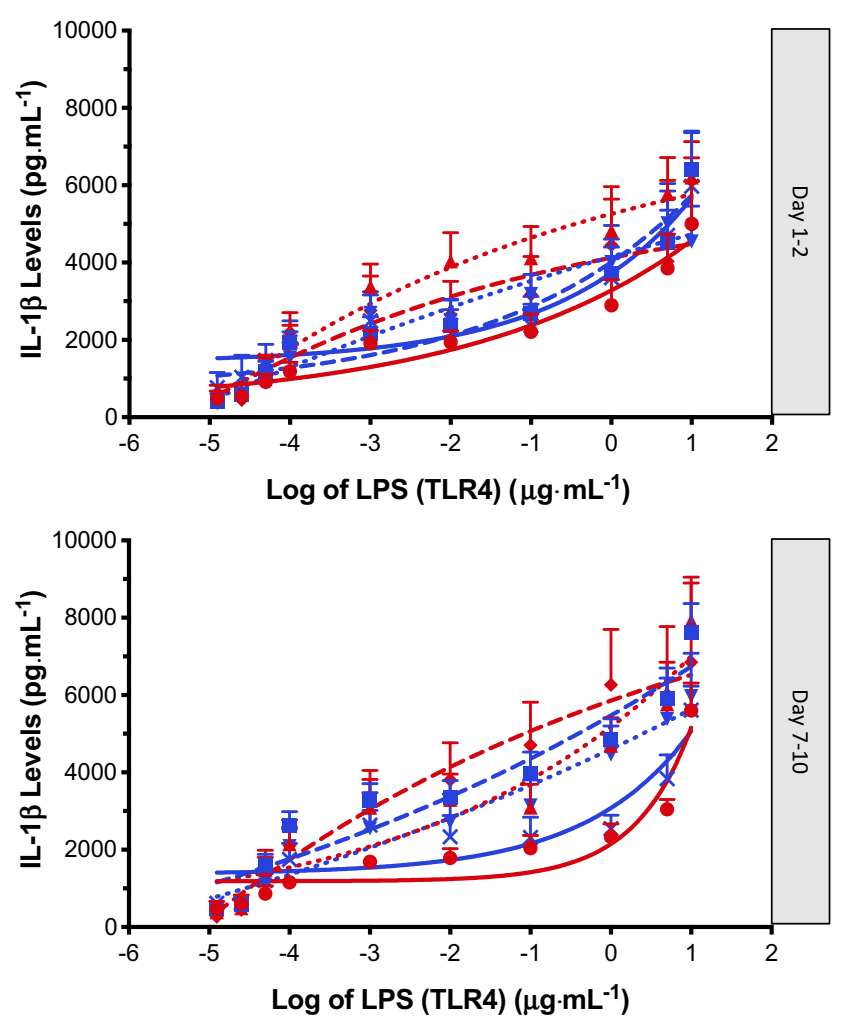

Figure $2 \mathrm{IL}-\mathrm{I} \beta$ release (Mean \pm SEM) following LPS (TLR4) stimulation ( $12.5 \mathrm{pg} \mathrm{mL}$ to $10 \mu \mathrm{g} \mathrm{mL}$ ) of PBMC's obtained from controls: no OC (red circle, solid line), controls: OC (blue square, solid line), dysmenorrhea: no OC (red triangle, dotted line), dysmenorrhea: OC (blue upside down triangle, dotted line), pelvic pain: no OC (red diamond, dashed line), and pelvic pain: OC (blue cross, dashed line). A four-parameter logistic dose-response curve has been fitted to each graph; data obtained from day I-2 and day 7-10 of each individuals' menstrual cycle.

in LS means for each main effect factor analysis for $\mathrm{EC}_{50}$ is represented graphically as a forest plot in Figure 5.

\section{Pairwise Comparisons of IL-I $\beta$ Release by Factor (Pain, OC Use and Day)}

Pairwise comparisons allow us to compare the variables across the entire participant cohort. Pairwise comparison of Pain versus No Pain (Table 3; Figure 5, Line 1) among all participants showed a statistically significant effect of pain $(\mathrm{p}=0.042)$. The LS mean $\mathrm{EC}_{50}$ in the no pain group (control) was $4.47 \mathrm{ng} \cdot \mathrm{mL}^{-1}$ compared with $2.08 \mathrm{ng} \cdot \mathrm{mL}^{-1}$ in the pain group, representing a difference of $2.39 \mathrm{ng} \cdot \mathrm{mL}^{-1}$ (pain - no pain) with $95 \%$ confidence limits from $-4.69 \mathrm{ng} \cdot \mathrm{mL}^{-1}$ to $-0.09 \mathrm{ng} \cdot \mathrm{mL} .^{-1}$ When considering the impact of this difference, the women with dysmenorrhea showed a large 2.15 -fold (95\% CI 4.69-0.09) increase in IL-1 $\beta$ release when compared with pain-free participants across both days.

Pairwise comparison of $\mathrm{OC}$ versus no OC (Table 3; Figure 5, Line 2) for all participants showed no significant effect of OC use ( $\mathrm{p}=0.98)$. The LS mean for $\mathrm{EC}_{50}$ in the OC user group was $3.29 \mathrm{ng} \cdot \mathrm{mL}^{-1}$ compared with $3.26 \mathrm{ng} \cdot \mathrm{mL}^{-1}$ in
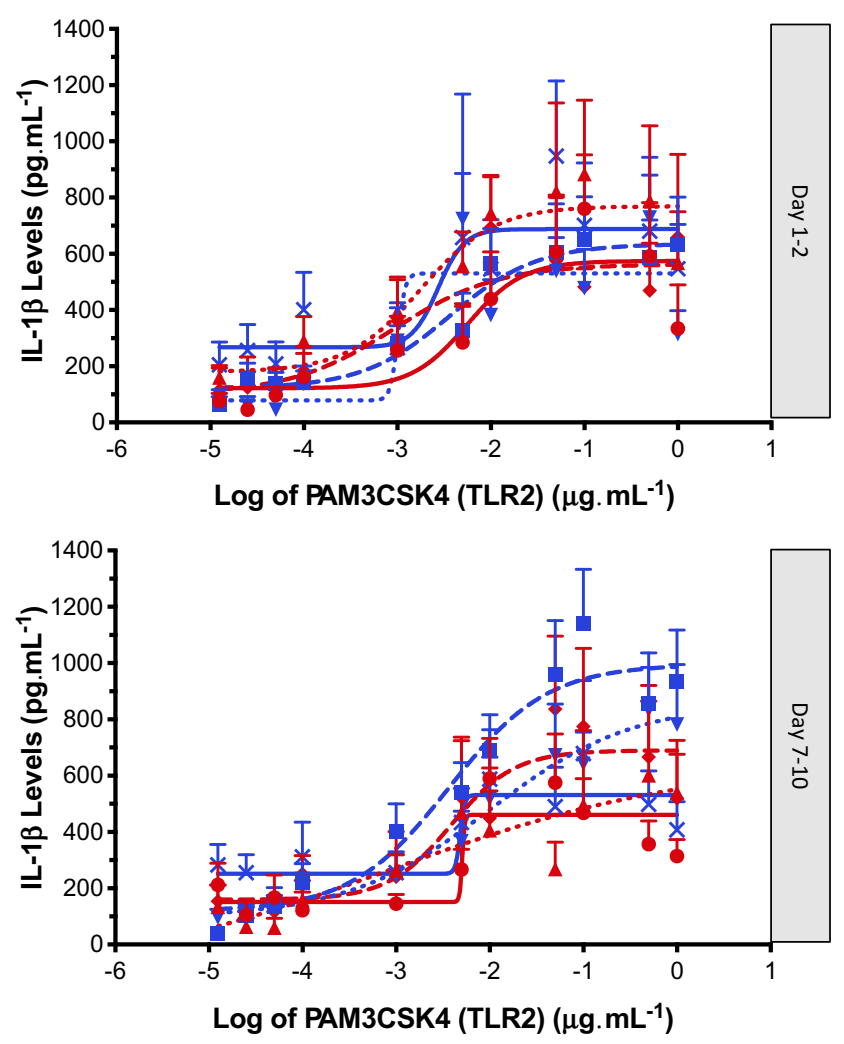

Figure $3 \mathrm{IL}-1 \beta$ release (Mean \pm SEM) following PAM3CSK4 (TLR2) stimulation (I2.5 pg $\mathrm{mL}$ to I $\mu \mathrm{g} \mathrm{mL}$ ) of PBMC's obtained from controls: no OC (red circle, solid line), controls: OC (blue square, solid line), dysmenorrhea: no OC (red triangle, dotted line), dysmenorrhea: OC (blue upside down triangle, dotted line), pelvic pain: no OC (red diamond, dashed line), and pelvic pain: OC (blue cross, dashed line). A four-parameter logistic dose-response curve has been fitted to each graph; data obtained from day I-2 and day 7-10 of each individuals' menstrual cycle.

the OC non-user group, representing a difference of $0.03 \mathrm{ng} \cdot \mathrm{mL}^{-1}$ (OC - no OC), with $95 \%$ confidence limits from $2.26 \mathrm{ng} \cdot \mathrm{mL}^{-1}$ to $2.33 \mathrm{ng} \cdot \mathrm{mL} .^{-1}$

Pairwise comparison of Menstrual Phase (Day 1-2) versus Mid Follicular Phase (Day 7-10) (Table 3; Figure 5, Line 3) for all participants showed no significant effect of Day ( $\mathrm{p}=0.22$ ). The LS mean for $\mathrm{EC}_{50}$ in the Day 1-2 group, was $2.80 \mathrm{ng} \cdot \mathrm{mL}^{-1}$ compared with $3.74 \mathrm{ng} \cdot \mathrm{mL}^{-1}$ in the Day $7-10$ group, representing a difference of $0.94 \mathrm{ng} \cdot \mathrm{mL}^{-1}$ (Day 1-2 - Day 7-10), with $95 \%$ confidence limits from $2.46 \mathrm{ng} \cdot \mathrm{mL}^{-1}$ to $0.59 \mathrm{ng} \cdot \mathrm{mL}^{-1}$

Pairwise comparison of Menstrual Phase (Day 1-2) versus Mid-Follicular Phase (Day 7-10) (Table 3; Figure 5, Line 5) among pain-free controls who were non-users of the OC showed no significant effect of Day $(\mathrm{p}=0.16)$. The LS mean for $\mathrm{EC}_{50}$ in the Day 1-2, no pain group was $3.12 \mathrm{ng} \cdot \mathrm{mL}^{-1}$ compared with $5.86 \mathrm{ng} \cdot \mathrm{mL}^{-1}$ in the Day 7-10, no pain group, representing a difference of $2.74 \mathrm{ng} \cdot \mathrm{mL}^{-1}$ (Day 1-2 - Day $7-10$ ) with $95 \%$ confidence limits from $6.55 \mathrm{ng} \cdot \mathrm{mL}^{-1}$ to $1.08 \mathrm{ng} \cdot \mathrm{mL}^{-1}$ 

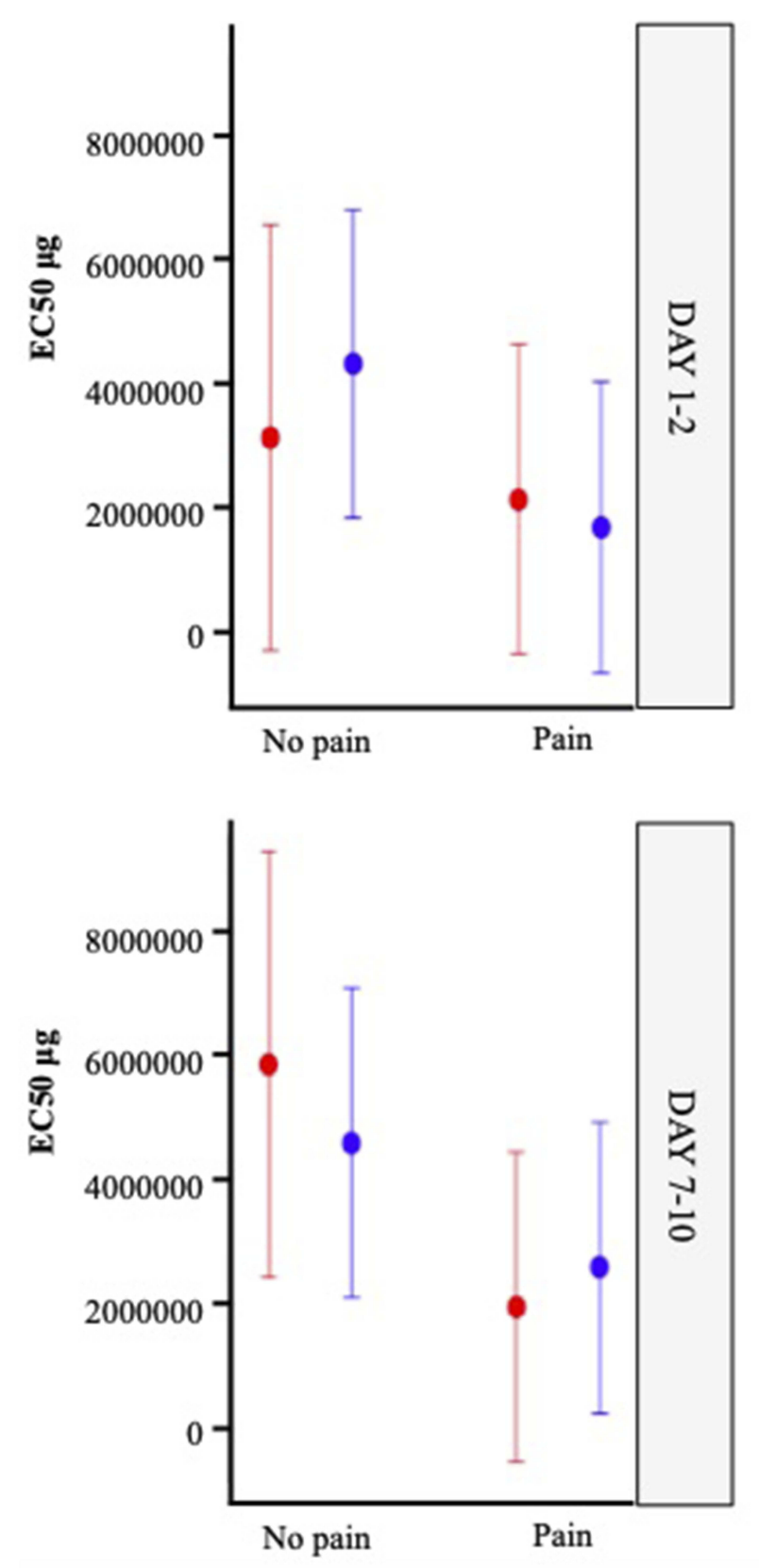

Figure 4 Least Squares means for EC50 with $95 \%$ confidence limits by factor using mixed model.

\section{Discussion}

To our knowledge, this data is the first to demonstrate an increase in systemic immune responsiveness in young women with dysmenorrhea-related pelvic pain to TLR agonists. This is a preliminary study with potentially wideranging clinical implications. Our initial hypothesis, that there would be a "pain response" to severe dysmenorrhea, as evidenced by a dynamic, increased responsiveness of PBMCs following TLR stimulation at the time of painful menstruation, was confirmed. However, the association was less than that demonstrated by Kwok et $\mathrm{al}^{23}$ in an older, undifferentiated cohort of both male and female chronic pain patients. While the direction of response for both TLR2 and TLR4 stimulation was similar, the effect size was greater with TLR4 stimulation.

Our research demonstrated a significant difference between the responsiveness of PBMCs to TLR4 stimulation (Table $3, \mathrm{p}=0.042$ ) in women with and without dysmenorrhea-related pelvic pain. The mechanism behind the upregulation of the innate immune system in these women with pain may involve factors that increase exposure of the uterus or peritoneal cavity to TLR stimulation, or that impair the immune response to normal TLR stimulation.

\section{Recurrent Retrograde Menstruation with Exposure of the Peritoneal Cavity to Endometrial Immune Cells and Microorganisms as a TLR Stimulus to the Innate Immune System}

Exposure of the peritoneal cavity to menstrual blood and debris via the process of retrograde menstruation through the fallopian tubes has already been demonstrated in 76-90\% of women. ${ }^{26}$ During the late secretory phase of the menstrual cycle, an influx of immune cells, including macrophages, arrives in the endometrium following the normal, premenstrual fall in progesterone. Menstrual fluid that reaches the peritoneal cavity includes blood, shed endometrial cells, immune cells and bacteria, including the gram-negative bacilli with cell walls comprised of LPS. ${ }^{27}$ As such, retrograde menstruation provides multiple opportunities for interaction with the innate immune system. ${ }^{28}$ Menstrual stromal cells have been identified in lymph nodes draining the uterus during menstruation providing further evidence of immune clearance of endometrial cells in menstrual fluid. ${ }^{29}$ Our research demonstrated an increased responsiveness of the innate immune system independent of the day of testing (Table 3, $\mathrm{p}=0.22$ ). This supports the presence of immune activation across the menstrual cycle, rather than purely in the presence of severe pain. These findings are consistent with the clinical studies by Slater, Vincent, Payne, Granot and As-Sanie ${ }^{30-34}$ who have demonstrated a reduced pain stimuli threshold in women with dysmenorrhea, present throughout the menstrual cycle, at both pelvic and extrapelvic sites, as measured by pressure pain threshold or functional MRI change. 
Table 3 Least Squares Means for EC50 (with 95\% Confidence Limits) and Significance $\left(^{*}\right)$ by Factor, Derived from Mixed Model Comparing Participants with Pain/No Pain, OC Use/Non-OC Use, Day I-2/Day 7-10 in Controls Who Were Non-OC Users, and Day I-2/Day 7-10 in All Participants

\begin{tabular}{|c|c|c|c|c|}
\hline & Pain [I] & No Pain [2] & $\begin{array}{l}\text { Difference } \\
{[I-2]}\end{array}$ & $\begin{array}{l}\mathbf{P} \\
\text { value* }\end{array}$ \\
\hline \multirow[t]{2}{*}{$\begin{array}{l}\text { LS mean EC50 } \\
(95 \% \mathrm{Cl})\end{array}$} & $\begin{array}{l}2.08 \\
(0.63-3.53)\end{array}$ & $\begin{array}{l}4.47 \\
(2.69-6.25)\end{array}$ & $\begin{array}{l}-2.39 \\
(-4.69,-0.09)\end{array}$ & $0.042^{*}$ \\
\hline & OC use [I] & No OC use [2] & & \\
\hline \multirow[t]{2}{*}{$\begin{array}{l}\text { LS mean EC50 } \\
(95 \% \mathrm{Cl})\end{array}$} & $\begin{array}{l}3.29 \\
(1.85-4.73)\end{array}$ & $\begin{array}{l}3.26 \\
(1.47-5.05)\end{array}$ & $\begin{array}{l}0.03 \\
(-2.26,2.33)\end{array}$ & 0.98 \\
\hline & Day I-2, no pain, no OC [I] & Day $7-10$, no pain, no OC [2] & & \\
\hline \multirow[t]{2}{*}{$\begin{array}{l}\text { LS mean EC50 } \\
(95 \% \mathrm{Cl})\end{array}$} & $\begin{array}{l}3.12 \\
(-0.31-6.55)\end{array}$ & $\begin{array}{l}5.86 \\
(2.43-9.28)\end{array}$ & $\begin{array}{l}-2.74 \\
(-6.55,1.08)\end{array}$ & 0.16 \\
\hline & Day I-2 [I] & Day 7-10 [2] & & \\
\hline $\begin{array}{l}\text { LS mean EC50 } \\
(95 \% \mathrm{Cl})\end{array}$ & $\begin{array}{l}2.80 \\
(1.44,4.17)\end{array}$ & $\begin{array}{l}3.74 \\
(2.38,5.11)\end{array}$ & $\begin{array}{l}-0.94 \\
(-2.46,0.59)\end{array}$ & 0.22 \\
\hline
\end{tabular}

\section{An Impaired Immune Response with}

\section{Reduced Clearing of Menstrual Debris} from the Peritoneal Cavity as a Stimulus to the Innate Immune System

While all women with an intact uterus menstruate, and many exhibit retrograde menstruation, not all women suffer severe dysmenorrhea. A healthy immune response may be required to clear the pelvis of menstrual debris promptly, and an impaired immune response may be associated with reduced clearing of menstrual debris. Persistent chronic inflammation associated with residual menstrual tissue could be a mechanism for increased pain. Such an impaired response would provide prolonged stimulation of TLRs,

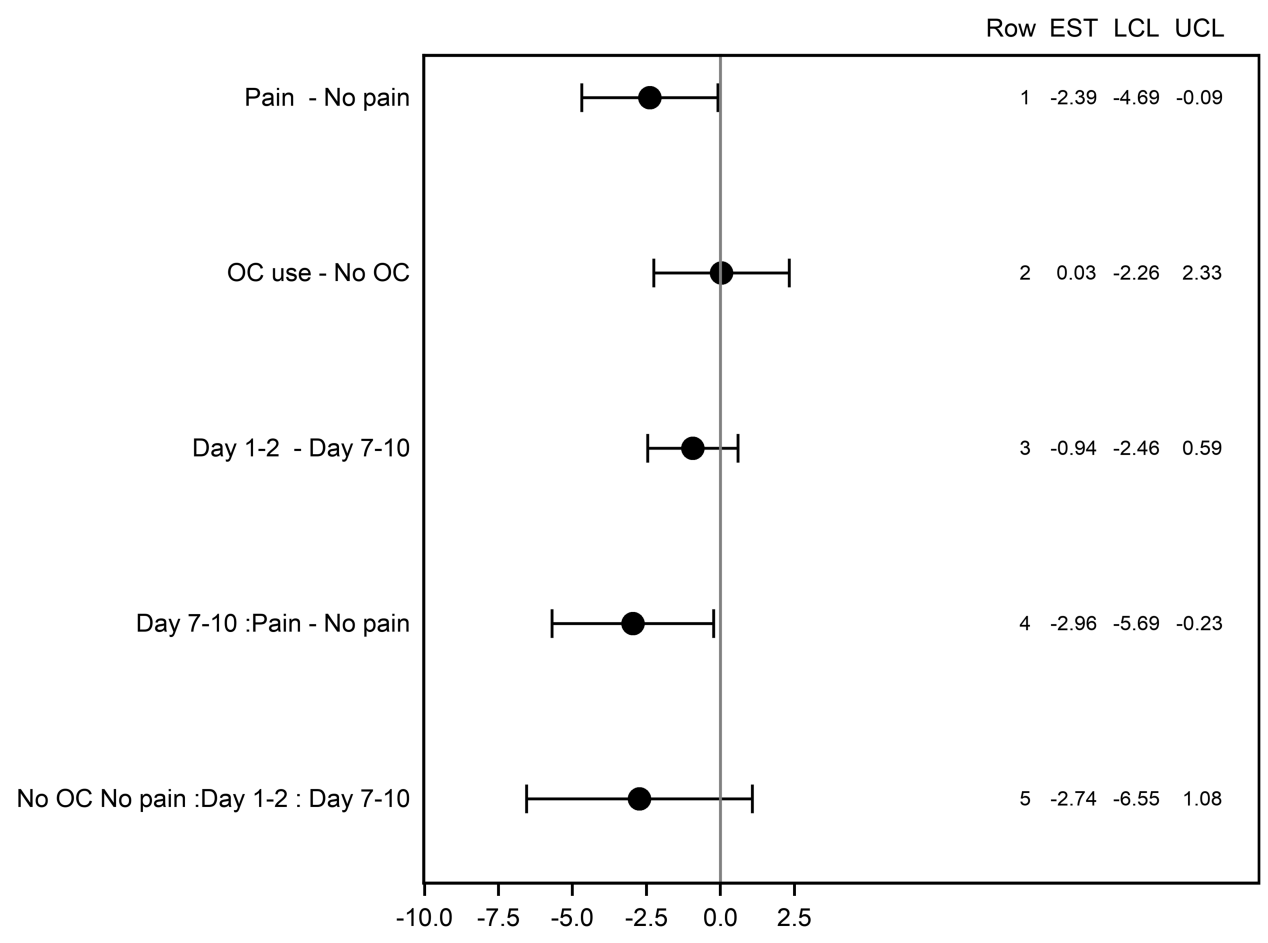

Figure 5 Forest Plot for difference in LS means for EC50 with $95 \%$ confidence limits by factor. 
with potential for enhanced immune system activation. Our finding that there was no significant difference between TLR4 responsiveness in the menstrual compared with the mid-follicular phase across our entire participant cohort (Figure 5, Line 3) suggests that the process of menstruation itself is not the sole contributor to TLR responsiveness. This finding was further investigated within the group of painfree controls who were non-OC users (Group 1). There was no significant difference between the responsiveness of PBMCs in the menstrual compared with the mid-follicular phase (Table $3, \mathrm{p}=0.16$ ) of pain-free controls who were nonOC users.

\section{Recurrent Stimulation of the Innate Immune System, via TLRs as a Potential Driver of Peripheral and Central Pain Sensitization}

It has been proposed that recurrent, monthly, painful menstruation may lead to the development of persistent pain states. ${ }^{23}$ Our study provides evidence that this effect may act in part via TLR4 mediated mechanisms. Preclinical models have demonstrated that glia assume a pro-inflammatory reactive state following activation by TLRs, and that TLR4 mediated inflammation contributes to central pain amplification via the dorsal horn of the spinal cord. ${ }^{35}$ The established ability of TLR antagonists to significantly reduce experimentally induced neuropathic pain in an animal model further supports these findings. ${ }^{36}$ In human studies, dysmenorrhea appears to be a central factor in the development of viscerovisceral hyperalgesia, and pain co-morbidities including migraine. ${ }^{15,37-39}$ Multiple studies have shown that even small peripheral immune challenges have a profound effect on pain enhancement, even in healthy subjects. ${ }^{40-42}$ Doses of LPS as low as $0.4 \mathrm{ng} \cdot \mathrm{kg}^{-1}$ delivered intravenously (IV) can provoke immune enhancement of pain responsiveness, which is below the threshold for a clinical response in healthy adults. This dose is also below the FDA approved level of LPS contamination $\left(1 \mathrm{ng} \cdot \mathrm{kg}^{-1}\right)$ in drug preparations and intravenous fluids. Our data, demonstrating an underlying sensitivity of PBMCs to TLR4 stimulation in women with dysmenorrhea-related pelvic pain provides a plausible mechanism by which cyclical exposure to menstruation engendering recurrent innate immune stimulation may predispose some women to chronic pelvic pain.

\section{The Oral Contraceptive as Treatment for Dysmenorrhea}

Despite its widespread use for the clinical management of dysmenorrhea, the exact mechanism by which the OC reduces pain in some, but not all women with dysmenorrhea remains uncertain. Our hypothesis that use of the $\mathrm{OC}$ would modulate the responsiveness of PBMCs in women with dysmenorrhea was not supported. Furthermore, we found no significant differences in IL- $1 \beta$ release between women who were users or non-users of the OC (Table 3, $\mathrm{p}=0.98$ ). It appears that the benefits some women derive from OC treatment for the management of dysmenorrhea is via pathways other than TLR-mediated immune system modulation. Alternatively, it may be that the OC normalizes the increased responsiveness of PBMCs to pain, masking the underlying pain pathology.

While our research found no significant difference between the responsiveness of PBMCs to TLR stimulation in women who were users or non-users of the $\mathrm{OC}$, this requires further research. It is known that the sensitivity of TLR4 receptors is increased by estrogen ${ }^{35,43}$. The OC is widely used by young women for a range of hormonal management and contraceptive purposes apart from dysmenorrhea, and an improved understanding of its immune effects would have wide-ranging implications for clinical practice. It is important to note that the women using the $\mathrm{OC}$ in our investigation were not selected on the basis of clinical benefit of $\mathrm{OC}$ use for pain. This limits the conclusions that can be drawn from our data.

\section{TLR Stimulation of PBMCs as a Blood Biomarker for Pain in Women with Dysmenorrhea}

While the evidence linking TLR mediated neuro-inflammation and chronic pain in animal models is compelling, ${ }^{35,44}$ its relevance to human pain conditions has been lacking, largely due to the inaccessibility of the human central nervous system (CNS) and the lack of a reliable, effective, human biomarker for pain or immune activation. Pain in humans has thus been a subjective experience, conventionally assessed by patient reports or rating scales. This lack of suitable biomarker hampers the development of new pain management options. It reduces our ability to predict which women are most at risk of pain progression, our ability to monitor the response to pain therapies and it confounds patient stratification for enriched clinical trials.

However, given the research findings by Kwok et $\mathrm{al}^{24}$ that the TLR response from PBMCs does indeed mirror similar 
changes in the spinal cord, the demonstration by Kwok et al and Schrepf et al ${ }^{17,23}$ that the technique we have used can indeed differentiate a human cohort of either chronic pain or bladder pain patients from controls, and our own research findings, we believe that the measurement of innate immune responsiveness has the potential to be a useful biomarker for pain in women with dysmenorrhea. Unlike our study, Kwok et $\mathrm{al}^{24}$ and Schrepf et $\mathrm{al}^{17}$ found the response to TLR2 stimulation to be a better discriminator of persistent pain status than the response to TLR4 stimulation. However, the participant cohort in Kwok and Schrepf's studies included confounding diagnostic variables, such as co-morbid medical conditions, drug or hormone use, male patients, and pain conditions outside the pelvis. For the potential of this test as a biomarker for pain to be realized, longitudinal intervention studies, ideally placebo controlled, using the biomarker would be required. This testing can be performed independently of the menstrual cycle stage, simplifying future translational clinical trial development. However, the wide variability between individual responses, and the time and resource intensive requirements of the laboratory procedure we have used, limit its practical use. While repeating the study with larger numbers of participants may further refine the research findings, we do not believe that this should be undertaken. Advances in TLR testing using single point analysis provide improved convenience over our research protocols, despite their lack of ability to measure dynamic PBMC responsiveness in individual patients. Our study has demonstrated that testing can be performed independently of the menstrual cycle stage, simplifying future translational clinical trial development.

\section{The Association Between Dysmenorrhea, Endometriosis and the Innate Immune System}

Despite our focus on the role of the innate immune system and the primary care presentation of dysmenorrhea, it is recognised that a proportion of our study participants with pain may have endometriosis. Endometriosis was found in $62 \%$ of 880 adolescents undergoing laparoscopy for severe dysmenorrhea in a meta-analysis of 15 studies. ${ }^{45}$ However, dysmenorrhea may occur without endometriosis, endometriosis may be present without pain, and pain may persist despite complete surgical excision of endometriotic lesions, showing that the association between endometriosis and dysmenorrhea should not be assumed to imply causality. $^{14,46}$
Endometriosis is recognized as an inflammatory condition, with an increase in IL- $1 \beta$ release both at a local and systemic level. ${ }^{4,48}$ Increased $E$. Coli colony formation with increased endotoxin (LPS) levels has been demonstrated in both menstrual blood and the peritoneal fluid of women with endometriosis, with endometrial cell growth enhanced by LPS administration. ${ }^{27}$ These findings prompted Khan et al to propose the "Bacterial contamination theory" for the development of endometriosis lesions, whereby contamination of menstrual fluid by $E$. Coli elicits peritoneal inflammation and predisposes to the development of endometriosis lesions. ${ }^{49}$ The prolonged presence of endometrial cells in the peritoneal cavity following menstruation has been demonstrated in women with endometriosis, and ascribed to either deficient cell-mediated immunity, ${ }^{50,51}$ or enhanced endometrial cell survival. Our research has investigated TLR activation from a pain, rather than an endometriosis lesion perspective. Despite this, it is possible that similar mechanisms, potentially involving impairment of the innate immune system and TLR activation, may predispose an individual to both conditions.

\section{Study Strengths and Weaknesses}

A strength of this study is the stringent exclusion criteria used, the lack of clinical co-morbidities, and the lack of confounding medications in this young, otherwise healthy, patient group. Another strength is the sampling at two stages of the menstrual cycle in each participant. This enables estimates of within-subject variability to be distinguished from between-subject and assay variability. Our study's demonstration that testing can be done during both the menstrual and mid-follicular phases of the menstrual cycle further enhances the applicability of this test to research and clinical practice.

Our study is an observational study with small group sizes, rather than an interventional study with large numbers of participants. Therefore, firm conclusions cannot be made. However, our study design was suitable given the exploratory nature of our research. As our participants were not randomized for OC usage, there is potential for selection bias. Future studies may choose to stratify groups according to participant-reported benefit or non-benefit of the OC for pain symptoms.

\section{Conclusion}

To our knowledge, this is the first study to demonstrate an ex vivo immune relationship in young women with dysmenorrhea-related pelvic pain. This response was at an early stage 
of their pain condition, and in a participant cohort free of confounding medical conditions or medications.

Our study found a significantly increased responsiveness of peripheral blood mononuclear cells to toll-like receptor stimulation using lipopolysaccharide $(\mathrm{p}=0.042)$. No difference was found in PBMC responsiveness in women who were users or non-users of the $\mathrm{OC}(\mathrm{p}=0.98)$. We propose that the mechanism of increased pain responsiveness in young women with dysmenorrhea results from a TLR-mediated activation of the immune system, after impaired clearing and prolonged exposure of the peritoneal cavity to menstrual and bacterial debris. This research provides a basis for the consideration and future development of novel treatments for dysmenorrhea and persistent pelvic pain.

Our study makes substantial progress in expanding our knowledge of the biological basis of dysmenorrhea-related pelvic pain, a field that has been under-researched when compared to its impact on individual women and society. This study identifies key parameters and therapeutic targets for further research and drug development in this area of unquestioned need.

\section{Acknowledgments}

Assistance with the preparation of article and figures: Dr Matilda Darling. Advice on editorial matters: Professor R Sussex.

\section{Author Contributions}

All authors contributed to data analysis, drafting and revising the article, gave final approval of the version to be published, and agree to be accountable for all aspects of the work.

\section{Funding}

The study was part-funded by the Australia New Zealand College of Anaesthetists (ANZCA) Research Foundation (Grant 15/013). Its contents are solely the responsibility of the authors and the funders had no role in the study design, data collection and analysis, decision to publish, or preparation of the manuscript.

\section{Disclosure}

Susan F Evans receives royalties from book authorship, has received payment from Pfizer and Bayer for educational presentations, and is a director of Alyra Biotech. Alyra Biotech is involved in the development of novel treatments for the management of pelvic pain. The submitted work is publication of research that was planned and initiated in November 2013. She also reports a patent (PCT/AU2018/
051383) pending to Alyra Biotech. Paul E Rolan is a shareholder in Havah Therapeutics and iXBiopharma, director and shareholder of Lipotek, consultant to Bionomics and Novartis, and has received payment for educational presentations from Novartis and Sequirus. Mark R Hutchinson is director of the Australian Research Council Centre of Excellence for Nanoscale BioPhotonics and the recipient of an ARC Future Fellowship (FT180100565). Dr Ann C Solterbeck is director of Statistical Revelations and receives payment from pharmaceutical companies outside this research area. The authors report no other conflicts of interest in this work.

\section{References}

1. Parker MA, Sneddon AE, Arbon P. The menstrual disorder of teenagers (MDOT) study: determining typical menstrual patterns and menstrual disturbance in a large population-based study of Australian teenagers. BJOG. 2010;117(2):185-192. doi:10.1111/ j.1471-0528.2009.02407.x

2. Ju H, Jones M, Mishra G. The prevalence and risk factors of dysmenorrhea. Epidemiol Rev. 2014;36:104-113. doi:10.1093/epirev/ mxt009

3. Soliman A, Surrey E, Bonafede M, Nelson J, Castelli-Haley J. Realworld evaluation of direct and indirect economic burden among endometriosis patients in the United States. Adv Ther. 2018;35 (3):408-423. doi:10.1007/s12325-018-0667-3

4. Alonso C, Coe CL. Disruptions of social relationships accentuate the association between emotional distress and menstrual pain in young women. Health Psychol. 2001;20(6):411-416. doi:10.1037/0278-6133. 20.6.411

5. Bajalan Z, Moafi F, Moradibaglooei M, Alimoradi Z. Mental health and primary dysmenorrhea: a systematic review. J Psychosom Obstet Gynaecol. 2018;1-10. doi:10.1080/0167482X.2018.1470619

6. Nnoaham KE, Hummelshoj L, Webster P, et al. Impact of endometriosis on quality of life and work productivity: a multicenter study across ten countries. Fertil Steril. 2011;96(2):366-373.e8. doi:10.1016/j.fertnstert. 2011.05.090

7. Baker FC, Lamarche LJ, Iacovides S, Colrain IM. Sleep and menstrual-related disorders. Sleep Med Clin. 2008;3(1):25-35. doi:10.1016/j.jsmc.2007.10.001

8. Rencz F, Péntek M, Stalmeier PF, et al. Bleeding out the quality-adjusted life years: evaluating the burden of primary dysmenorrhea using time trade-off and willingness-to-pay methods. Pain. 2017;158(11):2259-2267. doi:10.1097/j.pain.0000000000001028

9. Hardi G, Evans S, Craigie M. A possible link between dysmenorrhoea and the development of chronic pelvic pain. Aust $N$ Z J Obstet Gynaecol. 2014;54(6):593-596. doi:10.1111/ajo.12274

10. Westling AM, Tu FF, Griffith JW, Hellman KM. The association of dysmenorrhea with noncyclic pelvic pain accounting for psychological factors. Am J Obstet Gynecol. 2013;209(5):422.e1-422.e10. doi:10.1016/ j.ajog.2013.08.020

11. Jarrell J, Arendt-Nielsen L. Evolutionary considerations in the development of chronic pelvic pain. Am JObstet Gynecol. 2016 ;215(2):201.e1-4. doi:10.1016/j.ajog.2016.05.019.

12. Jarrell J, Arendt-Nielsen L. Allodynia and dysmenorrhea. J Obstetrics Gynaecol Canada. 2016;38(3):270-274. doi:10.1016/j.jogc.2016.02.001

13. Oladosu FA, Tu FF, Hellman KM. Nonsteroidal antiinflammatory drug resistance in dysmenorrhea: epidemiology, causes, and treatment. $\mathrm{Am}$ J Obstet Gynecol. 2018;218(4):390-400. doi:10.1016/j.ajog.2017.08.108 
14. Vercellini P, Fedele L, Aimi G, Pietropaolo G, Consonni D, Crosignani PG. Association between endometriosis stage, lesion type, patient characteristics and severity of pelvic pain symptoms: a multivariate analysis of over 1000 patients. Human Reprod. 2006;22(1):266-271. doi:10.1093/humrep/del339

15. Evans SF, Brooks TA, Esterman AJ, Hull ML, Rolan PE. The comorbidities of dysmenorrhea: a clinical survey comparing symptom profile in women with and without endometriosis. J Pain Res. 2018;11:3181-3194. doi:10.2147/JPR.S179409

16. Milligan ED, Watkins LR. Pathological and protective roles of glia in chronic pain. Nat Rev Neurosci. 2009;10(1):23-36. doi:10.1038/ $\operatorname{nrn} 2533$

17. Schrepf A, Bradley CS, O'donnell M, et al. Toll-like receptor 4 and comorbid pain in interstitial cystitis/bladder pain syndrome: a multidisciplinary approach to the study of chronic pelvic pain research network study. Brain Behavior Immun. 2015;49:66-74. doi:10.1016/j.bbi.2015.03.003

18. Belmonte L, Youmba SB, Bertiaux-Vandaële N, et al. Role of toll like receptors in irritable bowel syndrome: differential mucosal immune activation according to the disease subtype. PLoS One. 2012;7(8): e42777. doi:10.1371/journal.pone. 0042777

19. Mosser DM, Edwards JP. Exploring the full spectrum of macrophage activation. Nat Rev Immunol. 2010;10(6):460. doi:10.1038/nri2788

20. Gordon S, Taylor PR. Monocyte and macrophage heterogeneity. Nat Rev Immunol. 2005;5(12):953-964. doi:10.1038/nri1733

21. World Medical Association Declaration of Helsinki. Ethical principles for medical research involving human subjects. JAMA. 2013;310 (20):2191-2194. doi:10.1001/jama.2013.281053

22. Hjermstad MJ, Fayers PM, Haugen DF, et al. Studies comparing numerical rating scales, verbal rating scales, and visual analogue scales for assessment of pain intensity in adults: a systematic literature review. J Pain Symptom Manage. 2011;41(6):1073-1093. doi:10.1016/j. jpainsymman.2010.08.016

23. Kwok YH, Hutchinson MR, Gentgall MG, Rolan PE. Increased responsiveness of peripheral blood mononuclear cells to in vitro TLR 2, 4 and 7 ligand stimulation in chronic pain patients (Increased TLR responsiveness in pain patients). PloS one. 2012;7(8):e44232. doi:10.1371/journal. pone. 0044232

24. Kwok YH, Tuke J, Nicotra LL, Grace PM, Rolan PE, Hutchinson MR. TLR 2 and 4 responsiveness from isolated peripheral blood mononuclear cells from rats and humans as potential chronic pain biomarkers. PLoS One. 2013;8(10):e77799. doi:10.1371/journal.pone.0077799

25. Goutelle S, Maurin M, Rougier F, et al. The Hill equation: a review of its capabilities in pharmacological modelling. Fundam Clin Pharmacol. 2008;22(6):633-648. doi:10.1111/j.1472-8206.2008.00633.x

26. D'Hooghe TM, Debrock S. Endometriosis, retrograde menstruation and peritoneal inflammation in women and in baboons. Human Reprod Update. 2002;8(1):84-88.

27. Khan KN, Kitajima M, Hiraki K, Fujishita A, Ishimaru T, Masuzaki H. Escherichia coli in menstrual blood: an association with bacterial endotoxin and toll-like receptor 4 (TLR4)-mediated growth of endometriosis. J Reprod Immunol. 2006;71(2):152-153. doi:10.1016/j.jri.2006.08.030

28. Salamonsen LA, Lathbury LJ. Endometrial leukocytes and menstruation. Hum Reprod Update. 2000;6(1):16-27. doi:10.1093/humupd/6.1.16

29. Berbic M, Ng CHM, Black K, et al. A novel pilot study of endometrial stromal cells and immune cell populations in sentinel uterine-draining lymph nodes during the menstrual cycle and in endometriosis. Reprod Sci. 2013;20(11):1339-1348. doi:10.1177/1933719113485298

30. Granot M, Yarnitsky D, Itskovitz-Eldor J, Granovsky Y, Peer E, Zimmer EZ. Pain perception in women with dysmenorrhea. Obstetrics Gynecol. 2001;98(3):407-411. doi:10.1016/S00297844(01)01465-X

31. Vincent K, Warnaby C, Stagg CJ, Moore J, Kennedy S, Tracey I. Dysmenorrhoea is associated with central changes in otherwise healthy women. Pain. 2011;152(9):1966-1975. doi:10.1016/j.pain.2011.03.029
32. Slater H, Paananen M, Smith AJ, et al. Heightened cold pain and pressure pain sensitivity in young female adults with moderate-tosevere menstrual pain. Pain. 2015;156(12):2468-2478. doi:10.1097/j. pain.0000000000000317

33. As-Sanie S, Jin Hee K, Clauw DJ. Increased pressure pain sensitivity in women with endometriosis and chronic pelvic pain. Fertil Steril. 2009;92(3):S110. doi:10.1016/j. fertnstert.2009.07.1094

34. Payne LA, Rapkin AJ, Seidman LC, Zeltzer LK, Tsao JC. Experimental and procedural pain responses in primary dysmenorrhea: a systematic review. J Pain Res. 2017;10:2233-2246. doi:10.2147/ JPR.S143512

35. Nicotra L, Loram LC, Watkins LR, Hutchinson MR. Toll-like receptors in chronic pain. Exp Neurol. 2012;234(2):316-329. doi:10.1016/ j.expneurol.2011.09.038

36. Hutchinson MR, Zhang Y, Brown K, et al. Non-stereoselective reversal of neuropathic pain by naloxone and naltrexone: involvement of toll-like receptor 4 (TLR4. Eur J Neurosci. 2008;28 (1):20-29. doi:10.1111/j.1460-9568.2008.06321.x

37. Brinkert W, Dimcevski G, Arendt-Nielsen L, Drewes AM, WilderSmith OHG. Dysmenorrhoea is associated with hypersensitivity in the sigmoid colon and rectum. Pain. 2007;132:S46-S51. doi:10.1016/j. pain.2006.12.011

38. Harel Z. Dysmenorrhea in adolescents. Ann N Y Acad Sci. 2008;1135 (1):185-195. doi:10.1196/annals.1429.007

39. Smorgick N, Marsh CA, As-Sanie S, Smith YR, Quint EH. Prevalence of pain syndromes, mood conditions, and asthma in adolescents and young women with endometriosis. J Pediatr Adolesc Gynecol. 2013;26 (3):171-175. doi:10.1016/j.jpag.2012.12.006

40. Hutchinson MR, Buijs M, Tuke J, et al. Low-dose endotoxin potentiates capsaicin-induced pain in man: evidence for a pain neuroimmune connection. Brain Behav Immun. 2013;30:3-11. doi:10.1016/j. bbi.2013.03.002

41. Hutchinson MR. Want more pain? Just add a dash of endotoxin to enhance your clinical pain model. Brain Behav Immun. 2014;41:44-45. doi:10.1016/j.bbi.2014.06.008

42. Wegner A, Elsenbruch S, Maluck J, et al. Inflammation-induced hyperalgesia: effects of timing, dosage, and negative affect on somatic pain sensitivity in human experimental endotoxemia. Brain Behav Immun. 2014;41:46-54. doi:10.1016/j.bbi.2014.05.001

43. Nicotra L, Tuke J, Grace PM, Rolan PE, Hutchinson MR. Sex differences in mechanical allodynia: how can it be preclinically quantified and analyzed? Front Behav Neurosci. 2014;8:40. doi:10.3389/fnbeh.2014.00040

44. Grace PM, Rolan PE, Hutchinson MR. Peripheral immune contributions to the maintenance of central glial activation underlying neuropathic pain. Brain Behavior Immun. 2011;25(7):1322-1332. doi:10.1016/j. bbi.2011.04.003

45. Janssen EB, Rijkers AC, Hoppenbrouwers K, Meuleman C, D'Hooghe TM. Prevalence of endometriosis diagnosed by laparoscopy in adolescents with dysmenorrhea or chronic pelvic pain: a systematic review. Hum Reprod Update. 2013;19(5):570-582. doi:10.1093/ humupd/dmt016

46. Abbott JA, Hawe J, Clayton RD, Garry R. The effects and effectiveness of laparoscopic excision of endometriosis: a prospective study with 25 year followup. Human Reprod. 2003;18(9):1922-1927. doi:10.1093/humrep/deg275

47. Ahn SH, Khalaj K, Young SL, Lessey BA, Koti M, Tayade C. Immune-inflammation gene signatures in endometriosis patients. Fertil Steril. 2016;106(6):1420-1431.e7. doi:10.1016/j.fertnstert. 2016.07.005

48. Monsanto SP, Edwards AK, Zhou J, et al. Surgical removal of endometriotic lesions alters local and systemic proinflammatory cytokines in endometriosis patients. Fertil Steril. 2016;105(4):968-977. e5. doi:10.1016/j.fertnstert.2015.11.047 
49. Khan KN, Fujishita A, Hiraki K, et al. Bacterial contamination hypothesis: a new concept in endometriosis. Reprod Med Biol. 2018;17(2):125-133. doi:10.1002/rmb2.12083

50. Somigliana E, Viganò P, Gaffuri B, et al. Modulation of NK cell lytic function by endometrial secretory factors: potential role in endometriosis. Am J Reprod Immunol. 1996;36(5):295-300. doi:10.1111/j.16000897.1996.tb00179.x
51. Oosterlynck DJ, Cornillie FJ, Waer M, Vandeputte M, Koninckx PR. Women with endometriosis show a defect in natural killer activity resulting in a decreased cytotoxicity to autologous endometrium. Fertil Steril. 1991;56(1):45-51. doi:10.1016/S0015-0282(16)54414-8

\section{Publish your work in this journal}

The Journal of Pain Research is an international, peer reviewed, open access, online journal that welcomes laboratory and clinical findings in the fields of pain research and the prevention and management of pain. Original research, reviews, symposium reports, hypothesis formation and commentaries are all considered for publication. The manuscript management system is completely online and includes a very quick and fair peer-review system, which is all easy to use. Visit http:// www.dovepress.com/testimonials.php to read real quotes from published authors. 